Supporting Information

\title{
Neutral and Cationic Bismuth Compounds: Structure, Heteroaromaticity, and Lewis Acidity of Bismepines
}

\author{
Jacqueline Ramler, Klaus Hofmann, and Crispin Lichtenberg*
}

Institute of Inorganic Chemistry, Julius-Maximilians-University Würzburg, Am Hubland, 97074 Würzburg, Germany

Email: crispin.lichtenberg@uni-wuerzburg.de

Table of Contents

Single Crystal X-ray Diffraction Analysis................................. S02

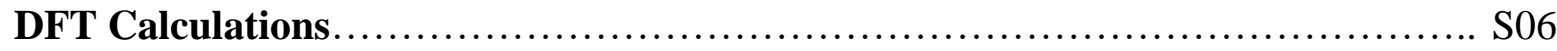

Lewis Acidity................................................................. 07

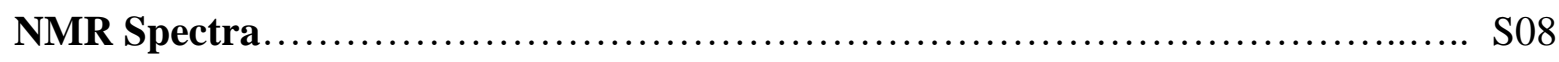

References................................................................... 17 


\section{Single Crystal X-ray Diffraction Analysis}

Graphic representations of the molecular structures of 3-Cl, a polymorph thereof (3-Cl'), and 3-I (as determined by single-crystal X-ray analysis) are given in Figures S1-S3. The graphics shown in Figure 2 of the main part are those for 3-Br.

a)

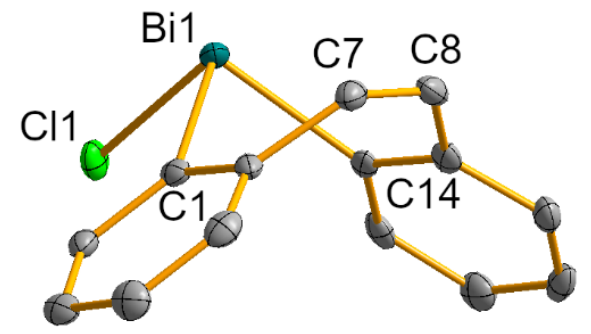

b)

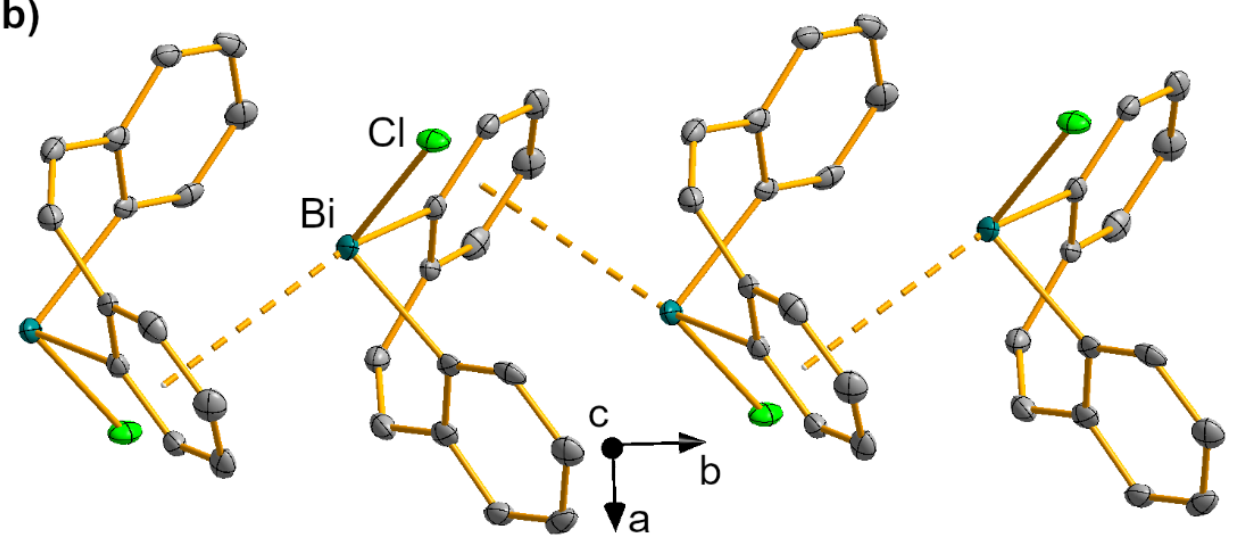

Figure S1. (a) Molecular structure of 3-Cl and (b) arrangement as one-dimensional coordination polymer in the solid state. Displacement ellipsoids are drawn at the 50\% probability level. Hydrogen atoms are omitted for clarity. One of two chemically identical but crystallographically independent formula units is shown.

Compound 3-Cl'. Compound 3-Cl' is a polymorph of compound 3-Cl and crystallized in the monoclinic space group $P 21 / c$ with $Z=4$ (Figure S2). The bond lengths within a molecular unit of 3-Cl' are within limits of error identical to those in 3-Cl. The bond angles are similar, albeit a smaller angle of $93.6^{\circ}$ was observed between the mean planes of the benzo groups in 3-Cl', when compared to 3-Cl (angle(C1-C6)/(C9-C14), 100.2 ${ }^{\circ}$. This may be ascribed to packing effects, since 3-Cl' shows intermolecular interactions that differ considerably from those in 3Cl. In compound 3-Cl', there are weak intermolecular $\mathrm{Bi}{ }^{\cdots} \mathrm{Cl}$ contacts with a $\mathrm{Bi} 1 \cdots \mathrm{Cl1}$ ' distance of $3.656 \AA$, which is $4 \%$ below the sum of the van der Waals radii (3.82 $\AA$ ). In addition, there are intermolecular $\mathrm{Bi} \cdots$ arene interactions similar to those in $\mathbf{3}-\mathbf{C l}, \mathbf{3}-\mathbf{B r}$, and 3-I. These intermolecular interactions lead to the formation of a coordination polymer of $\mathbf{3 - C l}$ ' in the solid state. It should be noted that the $\sigma^{*}(\mathrm{Bi}-\mathrm{Cl})$ orbital is not involved in any intermolecular bonding due to intramolecular $\pi(\mathrm{C}=\mathrm{C}) \rightarrow \sigma^{*}(\mathrm{Bi}-\mathrm{Cl})$ interactions as in 3-Cl, 3-Br, and 3-I. $\pi$-Stacking between benzo groups of neighboring strains of coordination polymers in $\mathbf{3 - C l}$ ' is present, but not discussed in detail.

Compound 3-I. Compound 3-I was discussed in the main part. It may be mentioned that additional weak contacts between the bismuth atom and the second benzo group (C9-C14) are

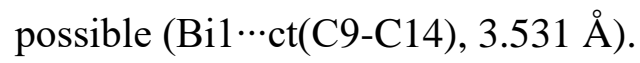


a)

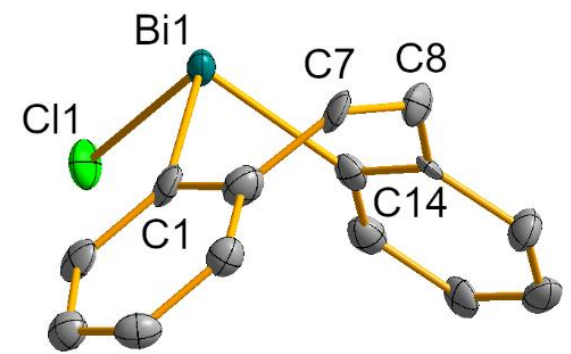

b)

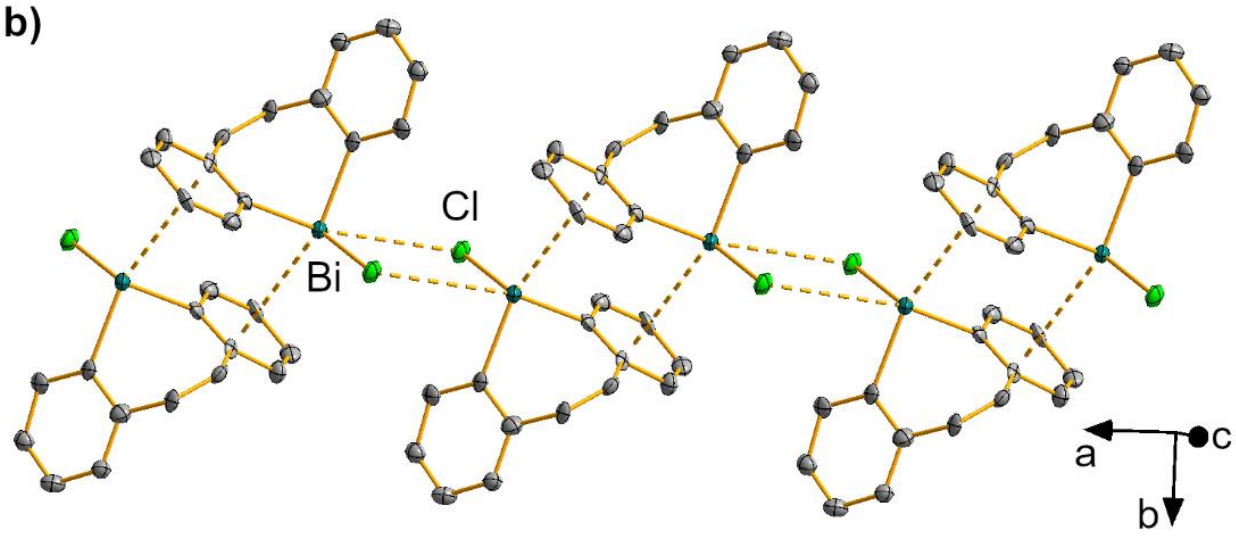

Figure S2. (a) Molecular structure of 3-Cl' and (b) arrangement as one-dimensional coordination polymers in the solid state. Displacement ellipsoids are drawn at the 50\% probability level. Hydrogen atoms are omitted for clarity. Selected bond lengths $(\AA)$, bond angles (deg), and interatomic distances $(\AA)$ : Bi1-Cl1, 2.522(4); Bi1-Cl1', 3.656(3); Bi1-C1,

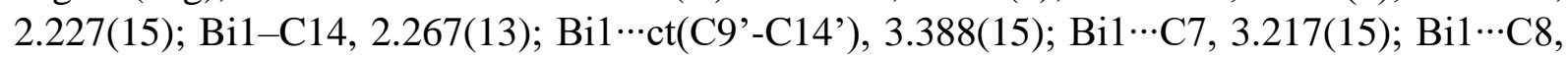
3.209(15); C1-Bi1-C14, 86.1(5); C1-Bi1-Cl1, 95.7(4); C14-Bi1-Cl1, 93.1(4); angle(C1C6)/(C9-C14), 93.6.

a)

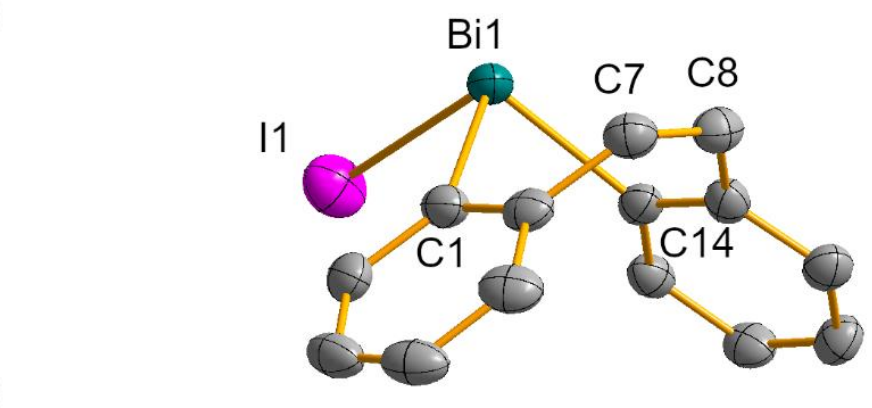

b)

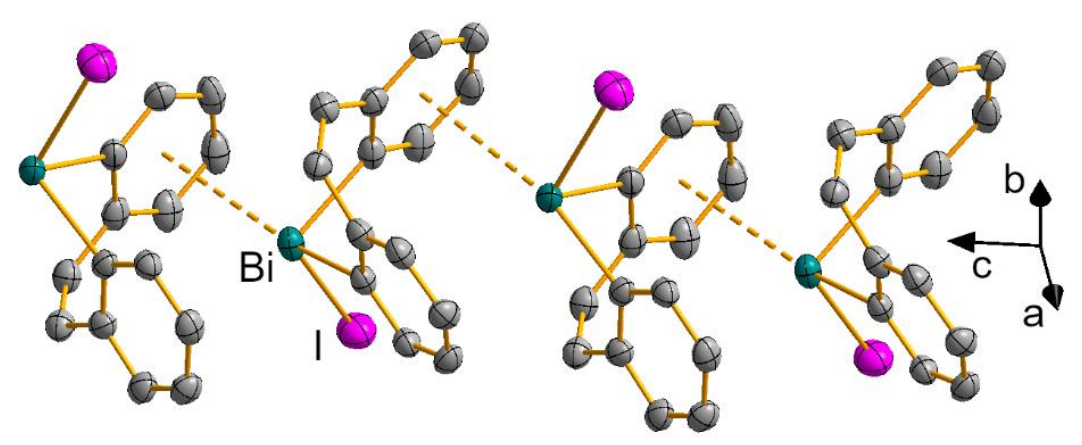

Figure S3. (a) Molecular structure of 3-I and (b) arrangement as one-dimensional coordination polymers in the solid state. Displacement ellipsoids are drawn at the $50 \%$ probability level. Hydrogen atoms are omitted for clarity. 
Compound 3-BF 4 . Compound $3-\mathbf{B F}_{4}$ crystallized in the monoclinic space group $P 2{ }_{1} / c$ with $Z$ $=4$ (Figure S4). The structural parameters of this compound are highly similar to those of the closely related species 3-OTf (see main part) and are thus not discussed in detail. As one exception from these close similarities, a larger angle between the mean planes of the benzo groups in $\mathbf{3}-\mathbf{B F}_{4}$ can be noted (angle $\left.(\mathrm{C} 1-\mathrm{C} 6) /(\mathrm{C} 9-\mathrm{C} 14), 135.5^{\circ}\right)$. Intermolecular $\mathrm{Bi} \cdots$ arene contacts in $\mathbf{3 - \mathbf { B F } _ { 4 }}$ are possible based on distance criteria.

a)
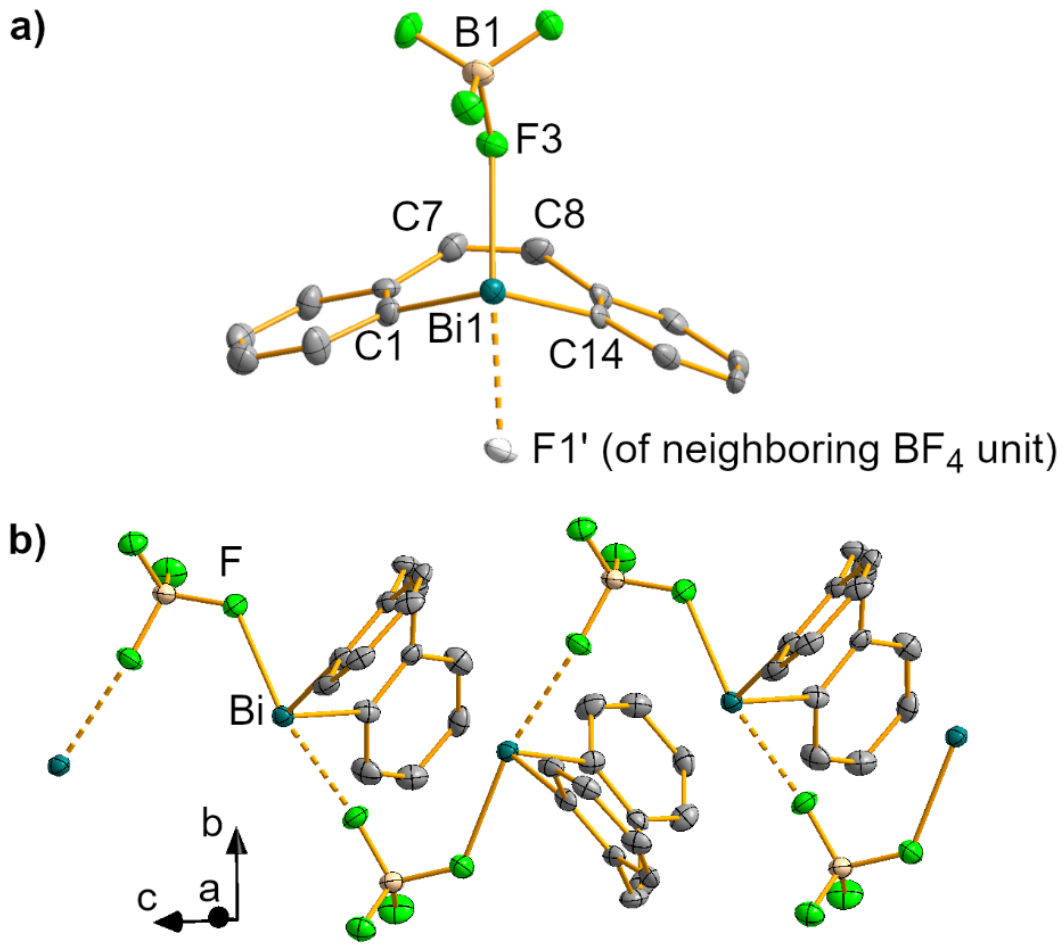

Figure S4. (a) Molecular structure of $\mathbf{3}-\mathbf{B F}_{\mathbf{4}}$ and (b) arrangement as one-dimensional coordination polymer in the solid state. Displacement ellipsoids are drawn at the $50 \%$ probability level. Hydrogen atoms are omitted for clarity. Atom exceeding one formula unit in a) is shown as a colorless ellipsoid. Selected bond lengths $(\AA)$ and angles (deg): Bi1-C1, 2.225(10); Bi1-C14, 2.223(8); Bi1-F3, 2.423(5); Bi1 $\cdots$ F1', 2.540(5); C1-Bi1-C14, 98.6(3); F3-Bi1-F1', 168.29(17); C1-Bi1-F3, 88.6(3); C14-Bi1-F3, 91.1(2); C1-Bi1-F1', 85.9(3); C14-Bi1-F1', 79.6(2); angle(C1-C6)/(C9-C14), 135.5.

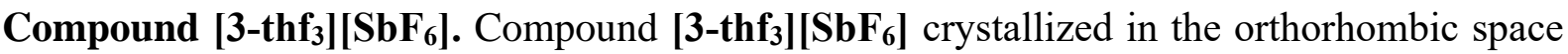
group $P 2{ }_{12}{ }_{12}$ with $Z=4$ (Figure S5). The bond angles in this compound are highly similar to

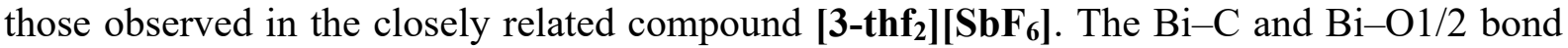
lengths in this compound are identical within limits of error to those in $\left[3-\mathbf{t h f}_{2}\right]\left[\mathbf{S b F}_{\mathbf{6}}\right]$. The additional thf ligand in [3-thf $\left.\mathbf{f}_{3}\right]\left[\mathbf{S b F}_{\mathbf{6}}\right.$ ] leads to a $\mathrm{Bi} \cdots \mathrm{O} 3$ distance of $3.02 \AA$, which is $16 \%$ below the sum of the van der Waals radii $(3.59 \AA)$. When this $\mathrm{Bi} \cdots \mathrm{O}$ contact is taken into account, a square pyramidal coordination geometry with $\mathrm{C} 14$ in the apical position is obtained $\left(\tau_{5}=0.15\right)$. 


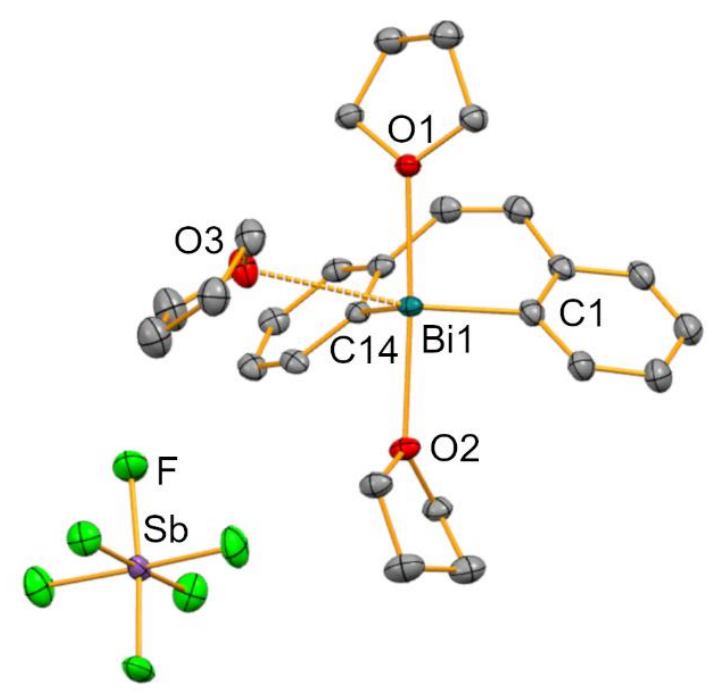

Figure S5. Molecular structure of [3-thf $\left.\mathbf{f}_{3}\right]\left[\mathbf{S b F}_{\mathbf{6}}\right]$ in the solid state. Displacement ellipsoids are drawn at the $50 \%$ probability level. Hydrogen atoms and one set of split positions of a positionally disordered $\mathrm{SbF}_{6}$ unit are omitted for clarity. Selected bond lengths $(\AA)$ and angles (deg): Bi1-C1, 2.232(10); Bi1-C14, 2.223(8); Bi1-O1, 2.411(6); Bi1-O2, 2.443(6); Bi1 ‥O3, 3.017(6); C1-Bi1-C14, 92.5(3); O1-Bi1-O2, 176.9(2); C1-Bi1-O3, 168.1(3); angle(C1C6)/(C9-C14), 124.3.

Compounds 2-solv. The molecular structure of compound $\mathbf{2}$ (with toluene in the crystal lattice) is discussed in the main part. In the course of our investigation on compound $\mathbf{2}$, a range of data sets was collected, all of which contain compound $\mathbf{2}$ with varying types of solvent molecules in the crystal lattice. The data is reported for completeness, but not discussed in detail, because the structural parameters of $\mathbf{2}$ are similar in all data sets.

The following structures have been obtained: $\mathbf{2} \cdot$ benzene, $\mathbf{2} \cdot \mathbf{C H}_{2} \mathbf{C l}_{2}, \mathbf{2} \cdot \mathbf{t h f 1}, \mathbf{2} \cdot \mathbf{t h f}$. 


\section{DFT Calculations}

For compounds 3-X $(\mathrm{X}=\mathrm{Cl}, \mathrm{Br}, \mathrm{I}), \pi(\mathrm{C}=\mathrm{C}) \rightarrow \sigma^{*}(\mathrm{Bi}-\mathrm{X})$ donor acceptor interactions were identified from second order perturbation theory analyses. One such interaction was identified for each compound and only this interaction was deleted when calculating the deletion energies $\left(E_{d e l}\right)$ that are given in the main part of the manuscript $\left(3-\mathbf{C l}: E_{d e l}=2.6 \mathrm{kcal} \mathrm{mol}^{-1} ; \mathbf{3 - B r}: E_{d e l}=\right.$ $2.8 \mathrm{kcal} \mathrm{mol}^{-1}$; 3-I: $E_{d e l}=2.9 \mathrm{kcal} \mathrm{mol}^{-1}$ ). No occupied MOs with significantly antibonding Bi $\cdots$ olefin character could be identified for 3-Cl, 3-Br, and 3-I.

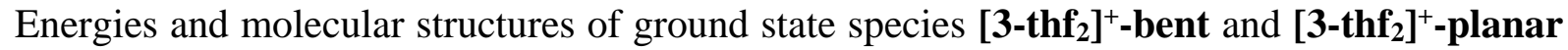
as well as the transition state TS that allows interconversion of these two species are shown in Figure S6. Free reaction enthalpies are shown in black, reaction enthalpies are shown in blue. The angles between the planes defined by the benzo groups of these species amount to $128.1^{\circ}$ $\left(\left[3-\text { thf }_{2}\right]^{+}\right.$-bent $), 180.0^{\circ}\left(\left[3-\text { thf }_{2}\right]^{+}\right.$-planar $)$, and $165.8^{\circ}$ (TS), respectively.

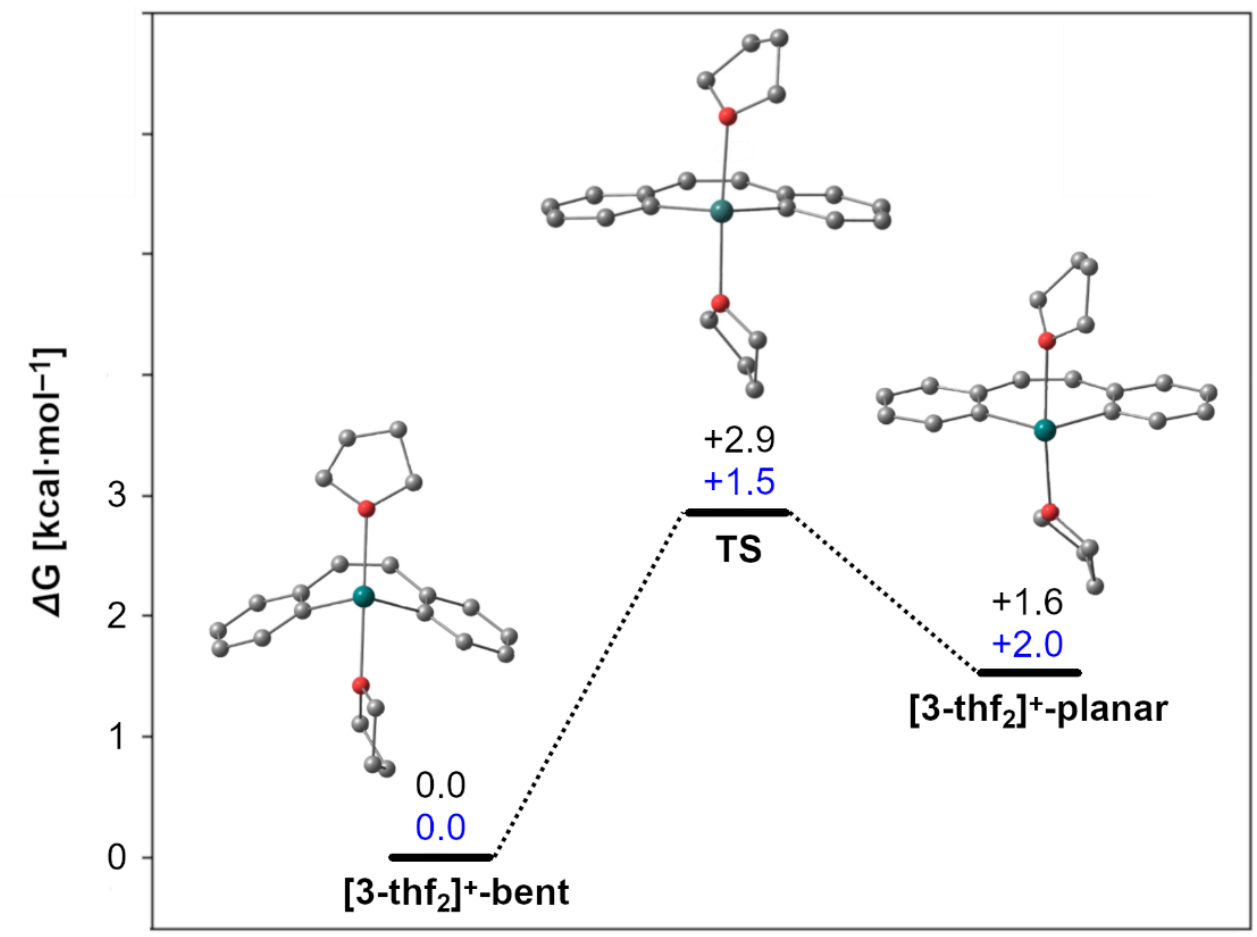

reaction coordinate

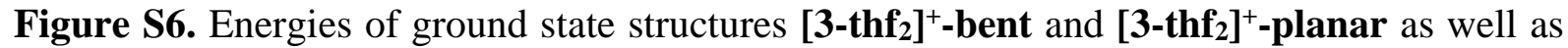
transition state TS. Free reaction enthalpies are shown in black, reaction enthalpies are shown in blue.

The structures of all calculated compounds are available in .xyz format. The energies of all calculated compounds are presented in Table S1. ${ }^{1}$

Table S1. Energies of calculated species.

\begin{tabular}{|c|c|c|c|c|}
\hline Entry & Compound & $\Delta H$ [hartree] & $\Delta G$ [hartree] & Imaginary frequencies \\
\hline 1 & 3-Cl & -559.740605 & -559.798289 & none \\
\hline 2 & 3-Br & -557.958712 & -558.017696 & none \\
\hline 3 & 3-I & -556.176086 & -556.235956 & none \\
\hline 4 & $\left.[3 \text {-thf }]_{2}\right]^{-}$-bent & -1009.275556 & -1009.359304 & none \\
\hline 5 & {$\left[3-\text { thf }_{2}\right]^{+}$-planar } & -1009.272351 & -1009.356818 & none \\
\hline 6 & TS & -1009.273211 & -1009.354742 & $v=-17.16 \mathrm{~cm}^{-1}$ \\
\hline 7 & {$[3]^{+}$-bent } & -544.488456 & -544.543219 & none \\
\hline 8 & {$[3]^{+}$-planar } & -544.502123 & -544.555760 & none \\
\hline
\end{tabular}




\section{Lewis Acidity}

THF and OPEt $t_{3}$ as competing Lewis bases. Titration experiments revealed that THF and $\mathrm{OPEt}_{3}$ compete for the Lewis acidic bismuth center in [3-thf $\left.\mathbf{f}_{2}\right]\left[\mathbf{S b F}_{\mathbf{6}}\right.$ ], when 1 or 2 equivalents of OPEt 3 are added to a solution of [3-thf $\left.\mathbf{f}_{2}\right]\left[\mathbf{S b F}_{6}\right]$ in $\mathrm{CD}_{2} \mathrm{Cl}_{2}$ (Figure S15). Addition of the second equivalent of OPEt3 results in chemical shifts of the THF molecules that suggest no interactions between the bismuth Lewis acid and THF. 


\section{NMR Spectra}
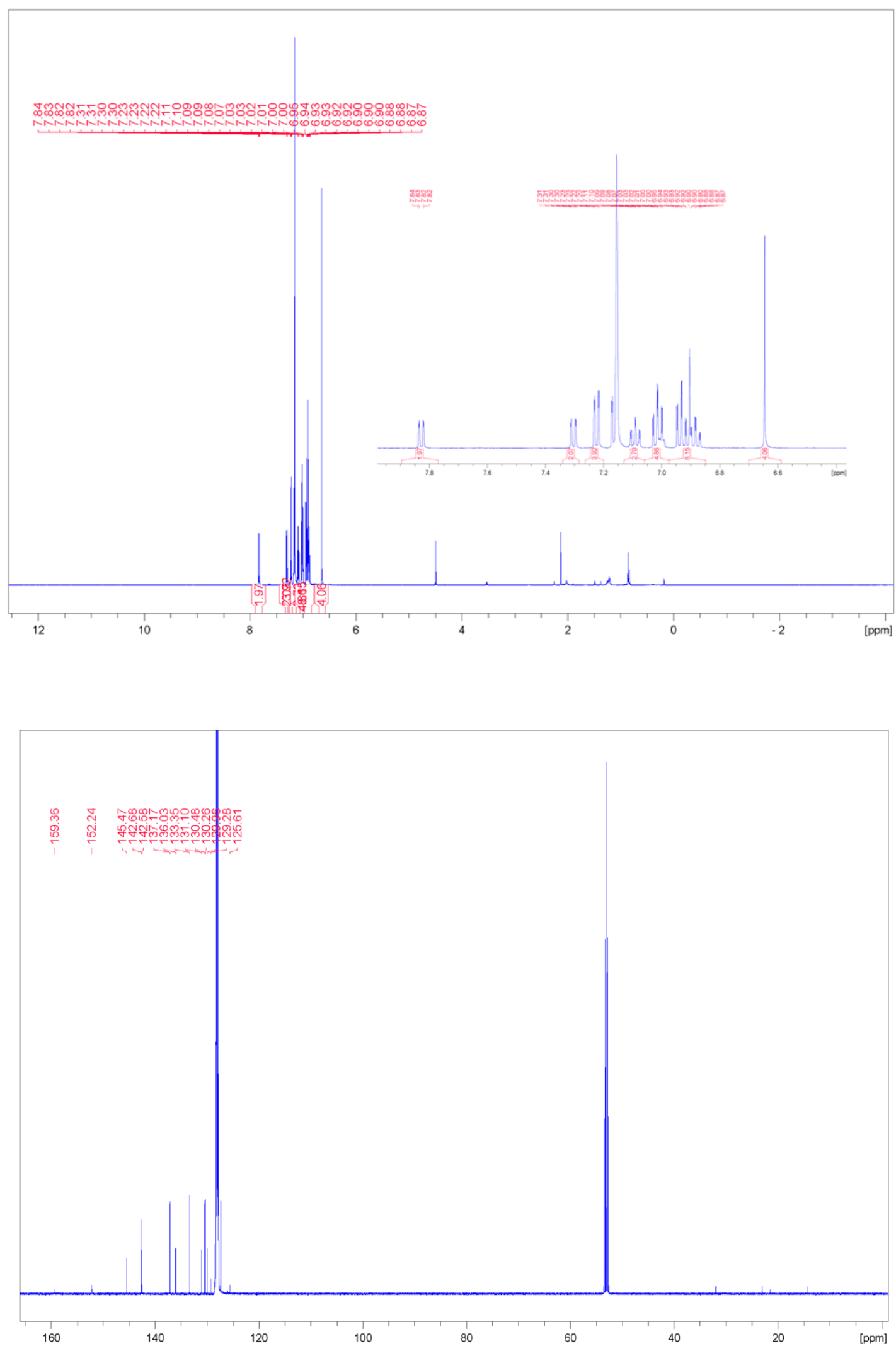

Figure S7. ${ }^{1} \mathrm{H}$ and ${ }^{13} \mathrm{C}$ NMR spectra of 2 in $\mathrm{C}_{6} \mathrm{D}_{6} / \mathrm{CD}_{2} \mathrm{Cl}_{2}$ (6:1). 

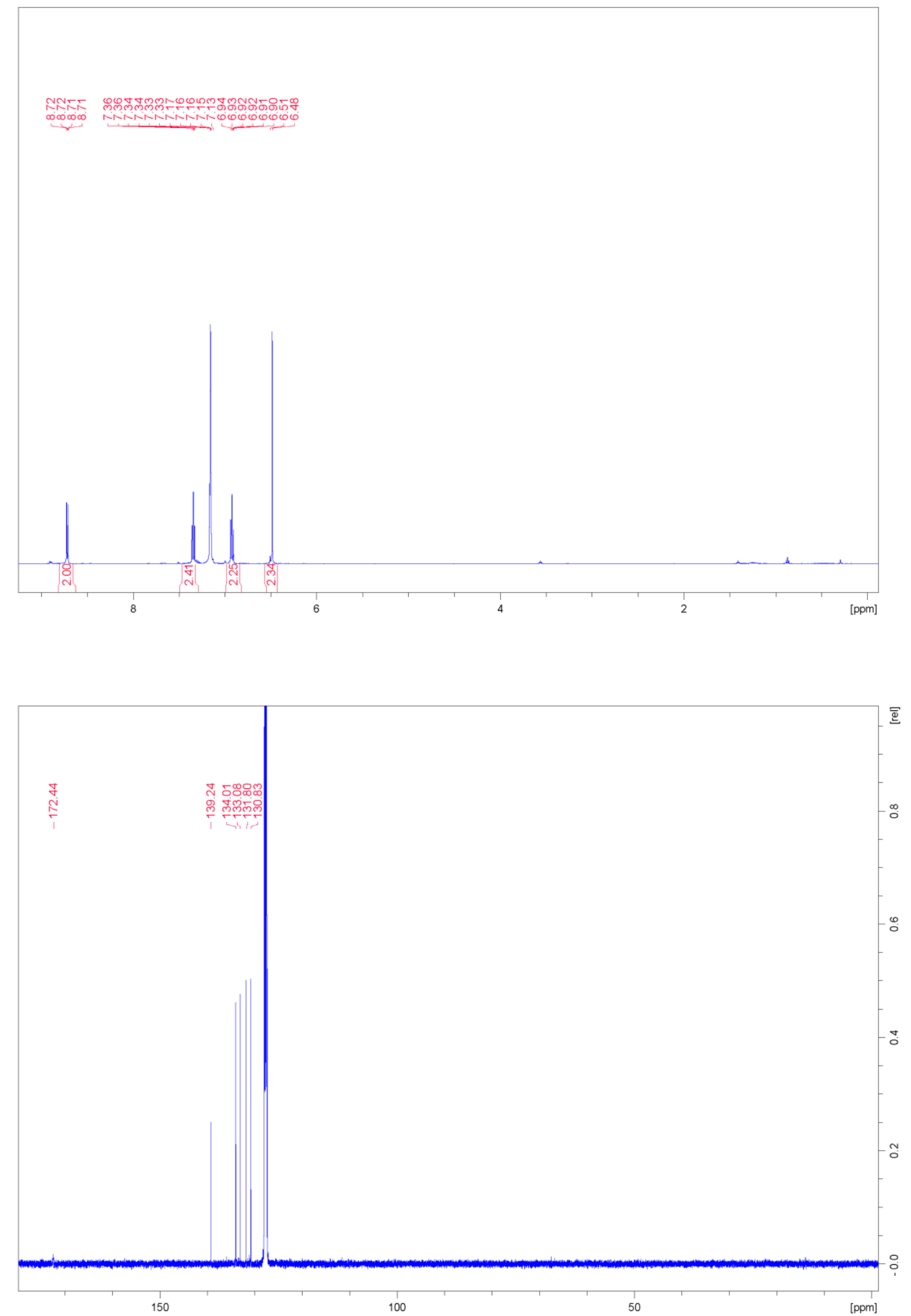

Figure S8. ${ }^{1} \mathrm{H}$ and ${ }^{13} \mathrm{C}$ NMR spectra of 3-Cl in $\mathrm{C}_{6} \mathrm{D}_{6}$. 

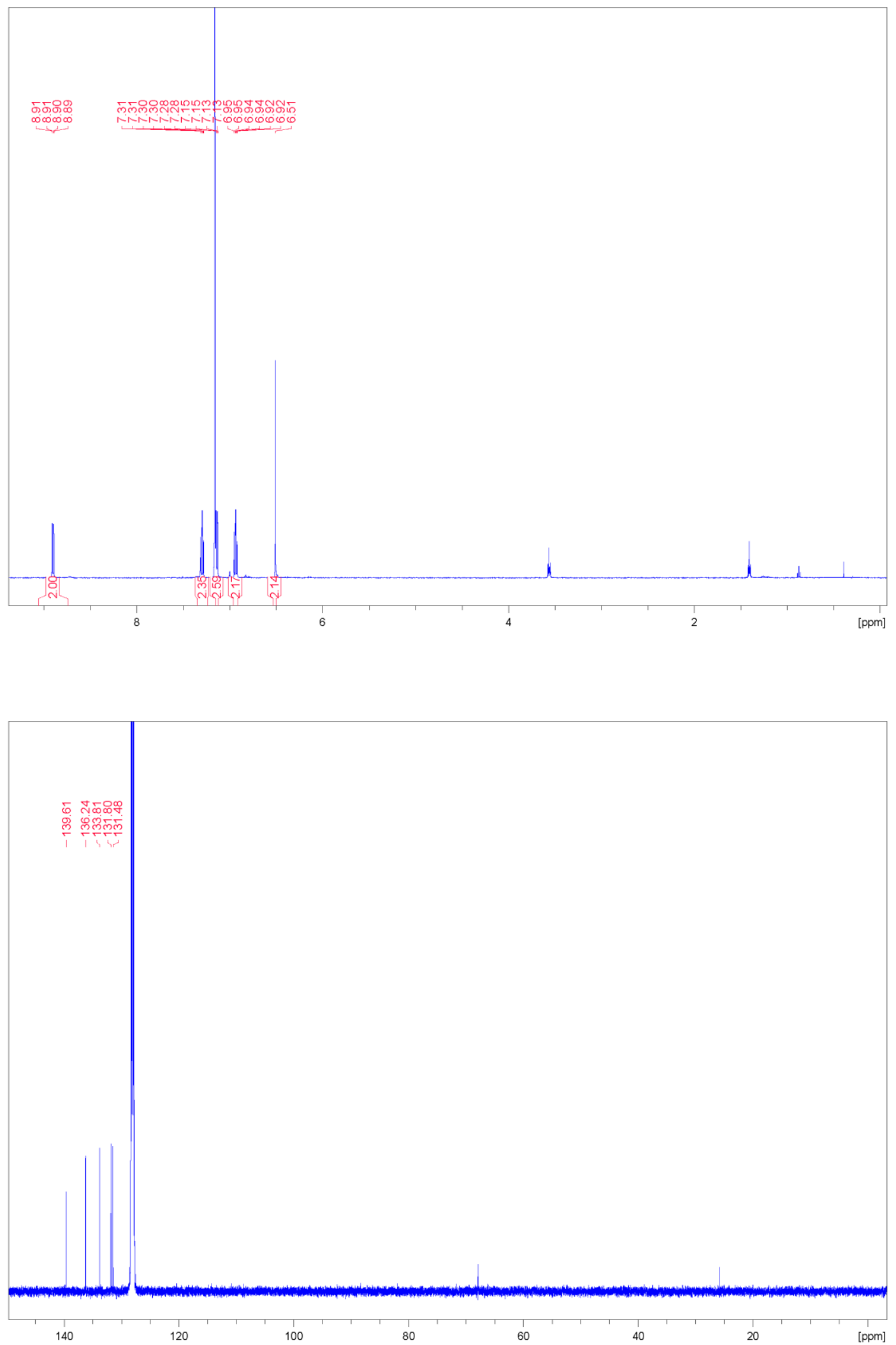

Figure S9. ${ }^{1} \mathrm{H}$ and ${ }^{13} \mathrm{C}$ NMR spectra of 3-Br in $\mathrm{C}_{6} \mathrm{D} 6$. 

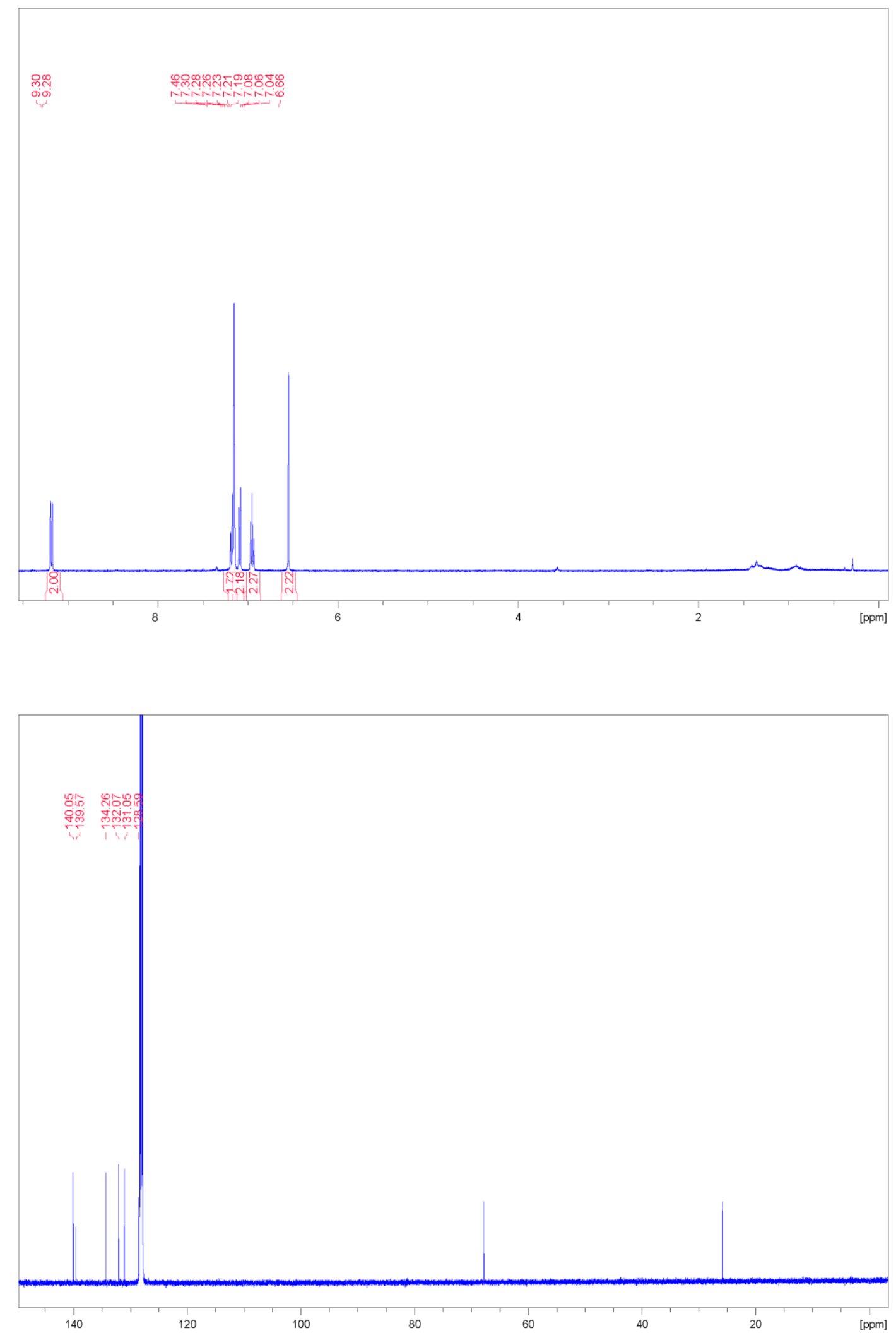

Figure S10. ${ }^{1} \mathrm{H}$ and ${ }^{13} \mathrm{C}$ NMR spectra of 3-I in $\mathrm{C}_{6} \mathrm{D}_{6}$. 

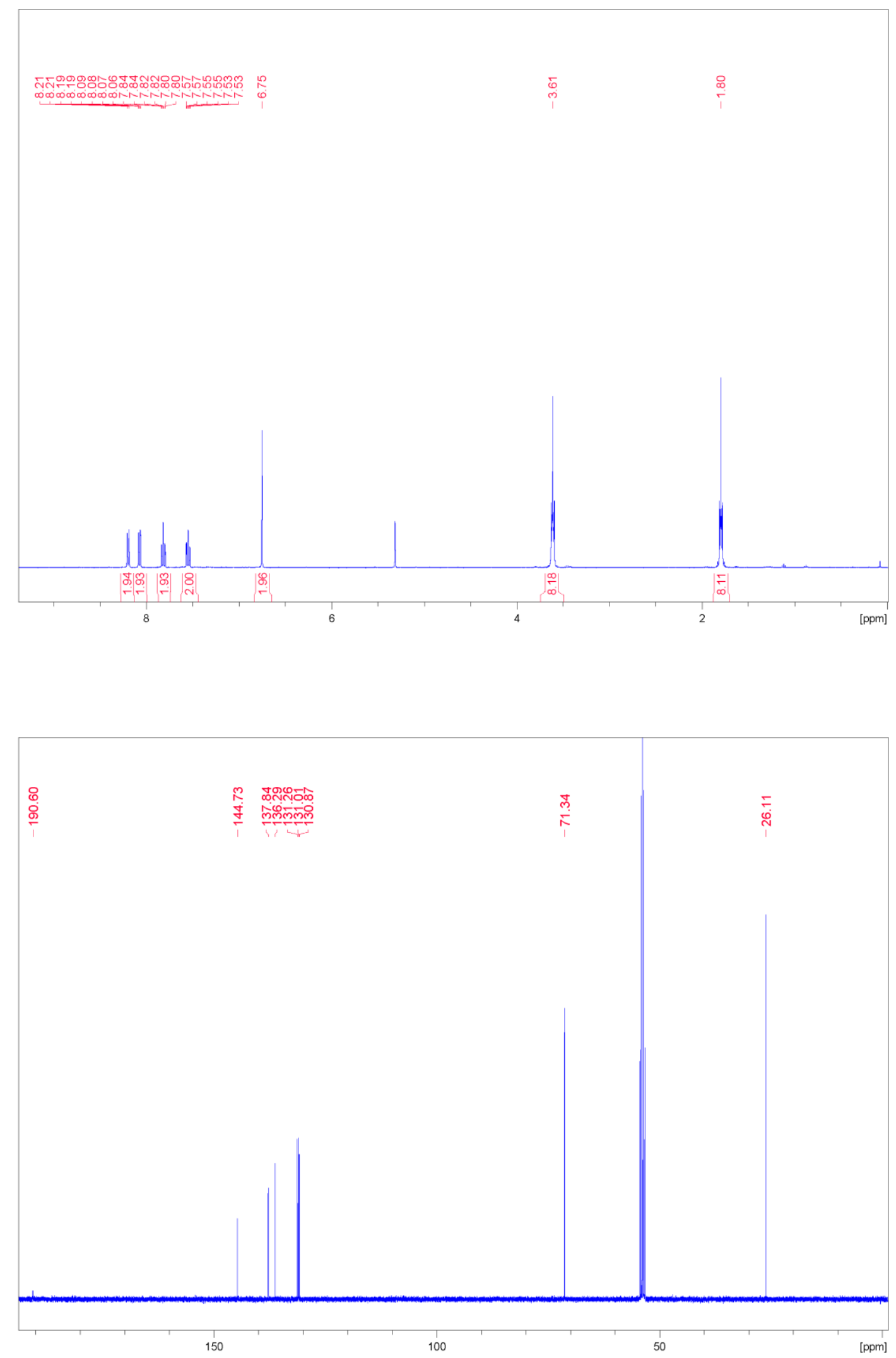

Figure S11. ${ }^{1} \mathrm{H}$ and ${ }^{13} \mathrm{C}$ NMR spectra of [3-thf 2$]\left[\mathbf{S b F}_{6}\right]$ in $\mathrm{CD}_{2} \mathrm{Cl}_{2}$. 


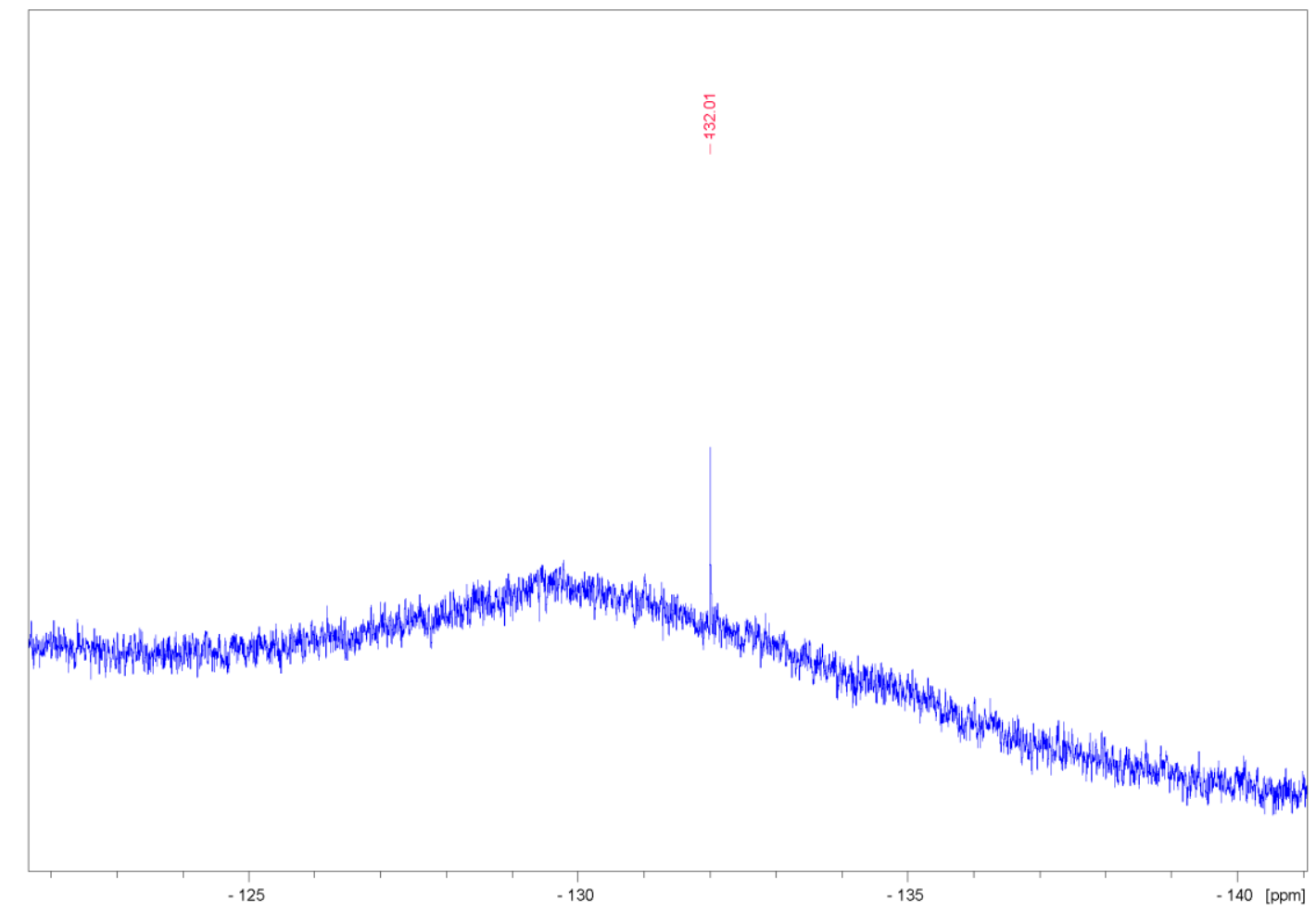

Figure S12. ${ }^{19} \mathrm{~F}$ NMR spectrum of $\left[3-\mathbf{t h f}_{2}\right]\left[\mathrm{SbF}_{\mathbf{6}}\right]$ in $\mathrm{CD}_{2} \mathrm{Cl}_{2}$. 

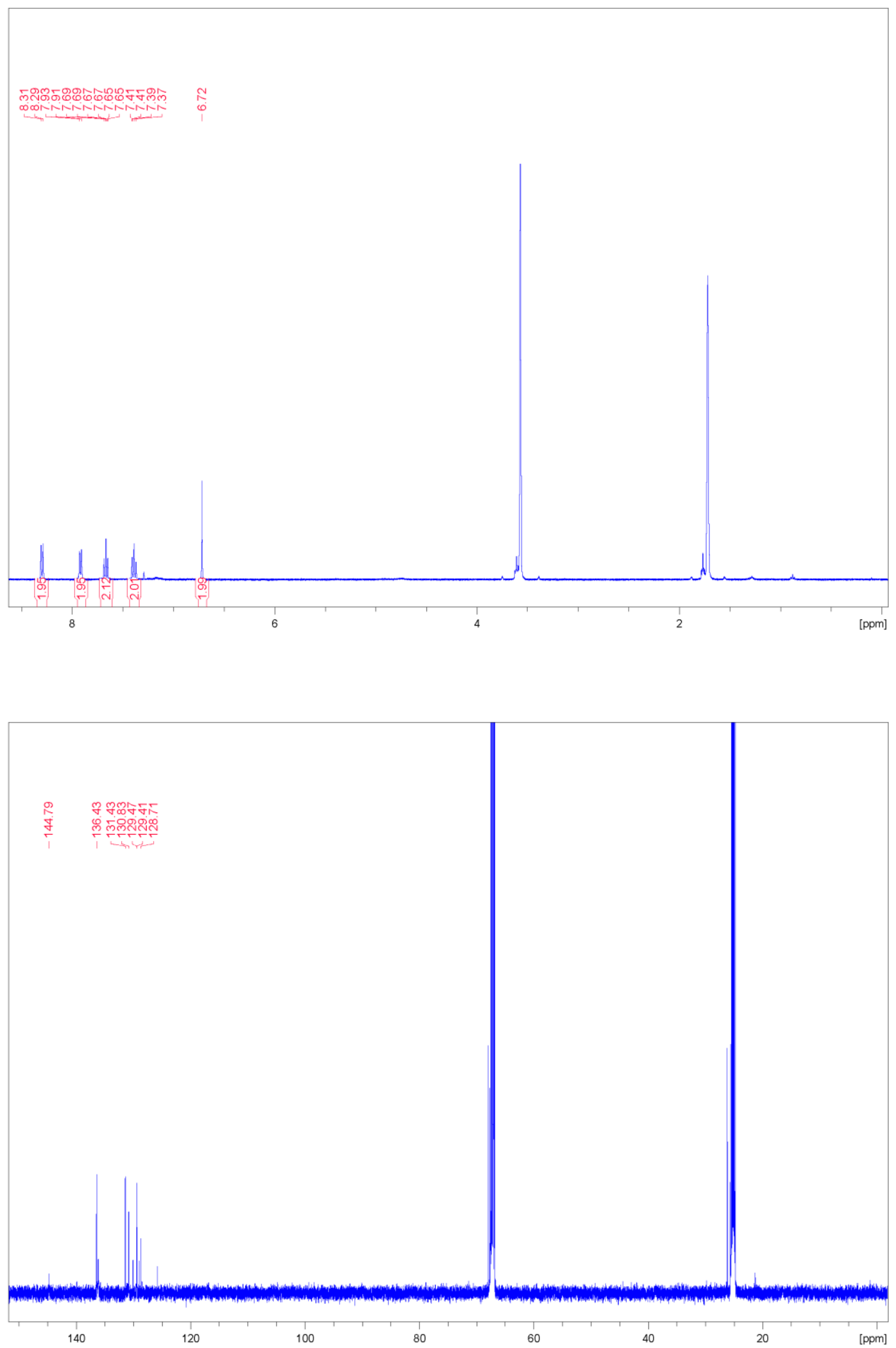

Figure S13. ${ }^{1} \mathrm{H}$ and ${ }^{13} \mathrm{C}$ NMR spectra of 3-OTf in THF- $d 8$. 


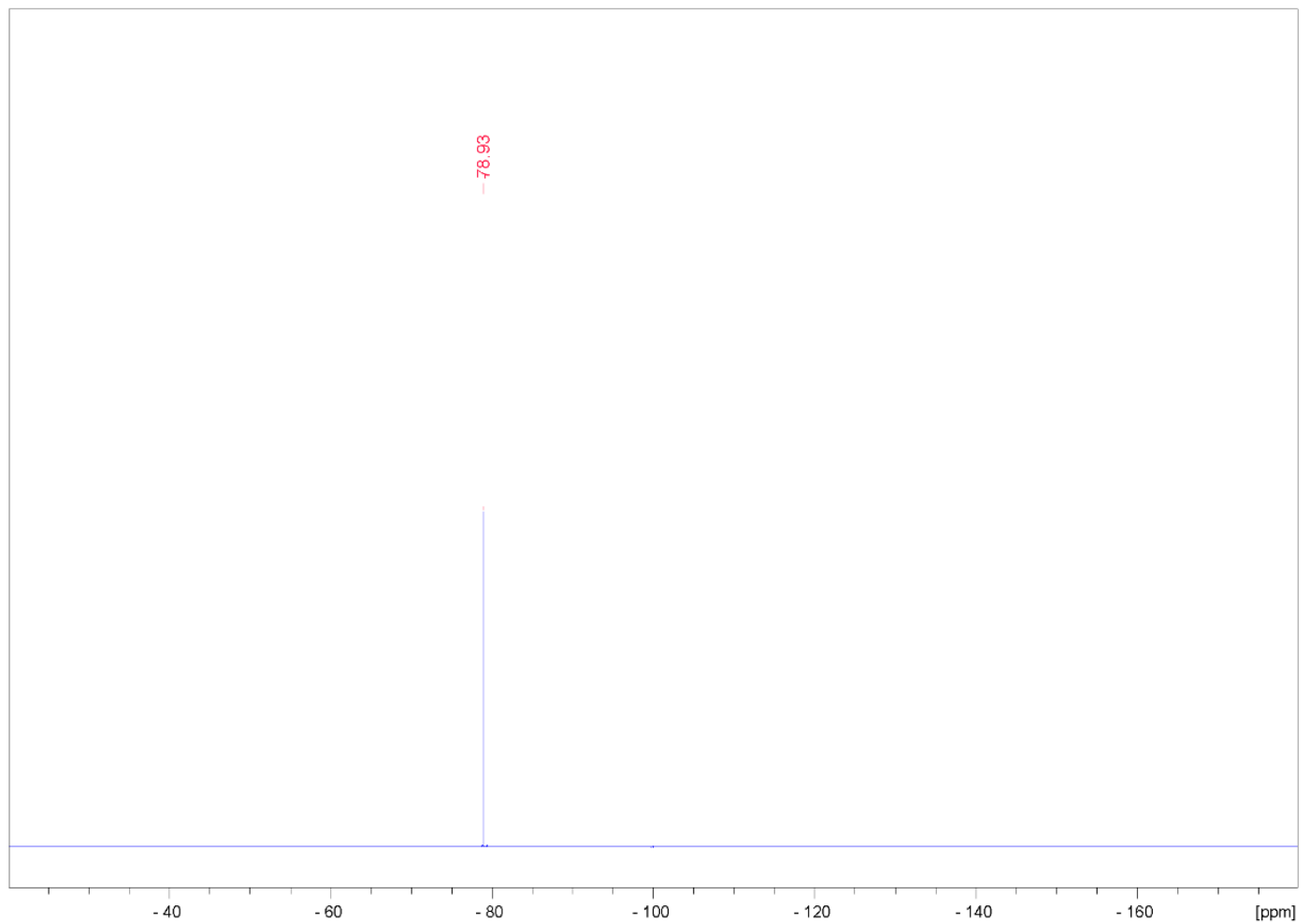

Figure S14. ${ }^{19}$ F NMR spectrum of 3-OTf in THF- $d s$. 
c)
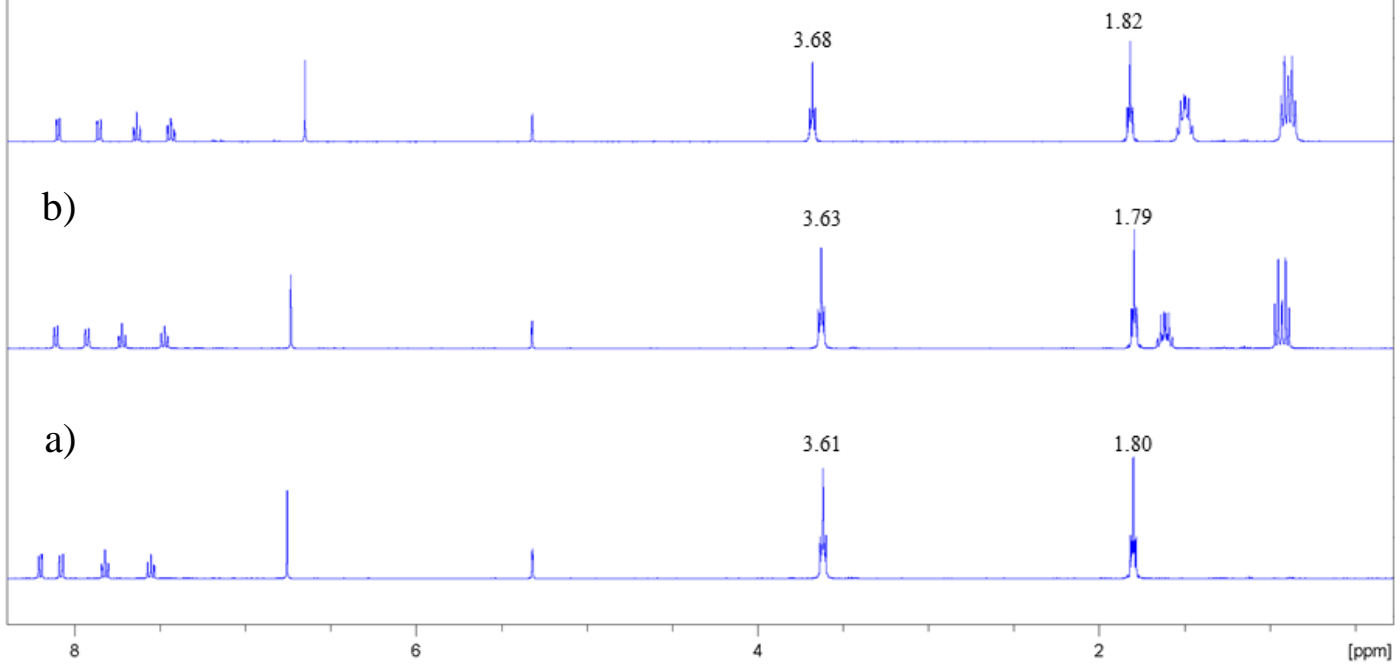

c)

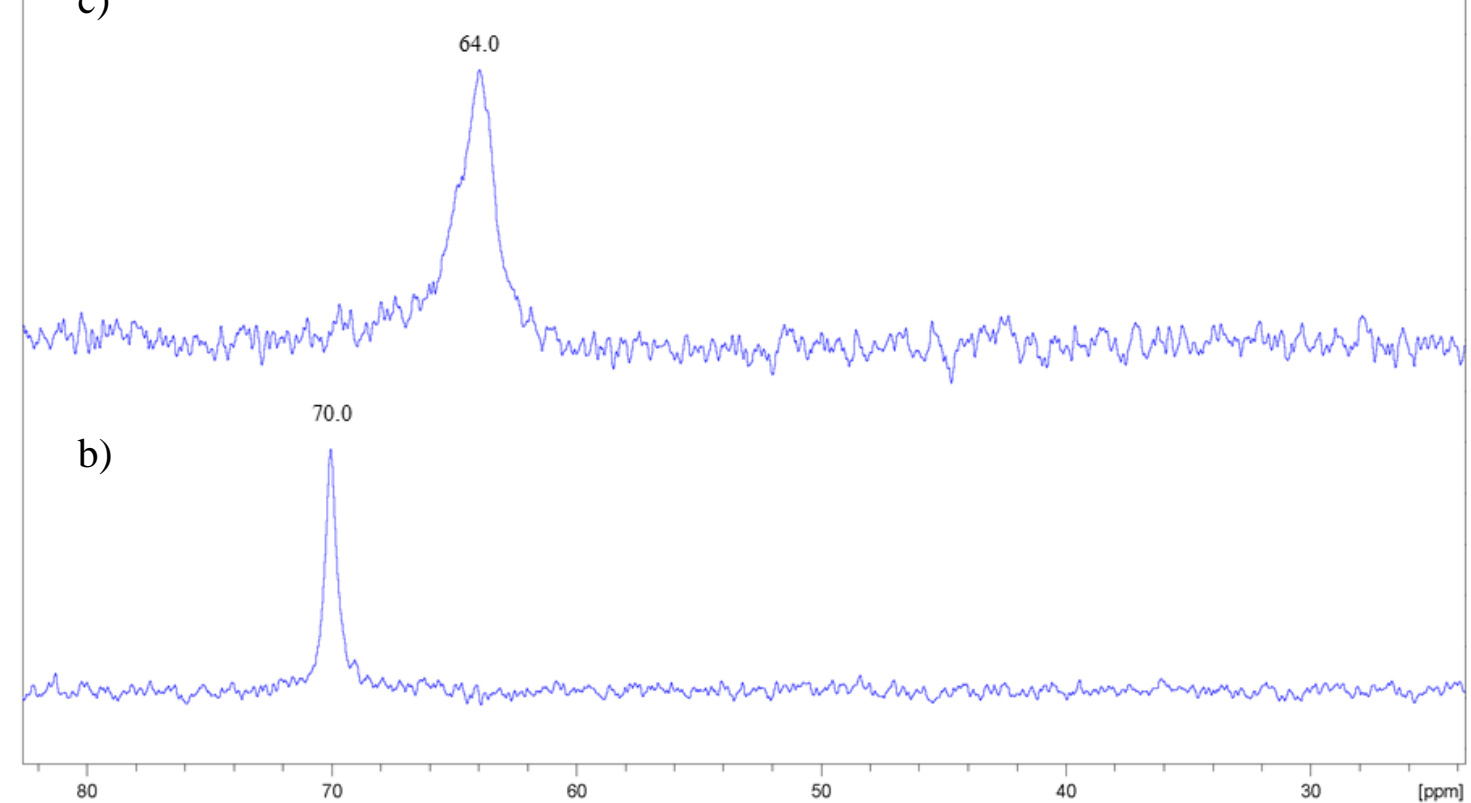

Figure S15. Top: ${ }^{1} \mathrm{H}$ NMR spectra of [3-thf $\left.\mathbf{f}_{2}\right]\left[\mathbf{S b F}_{\mathbf{6}}\right]$ in $\mathrm{CD}_{2} \mathrm{Cl}_{2}$ (a: without additives, b: with

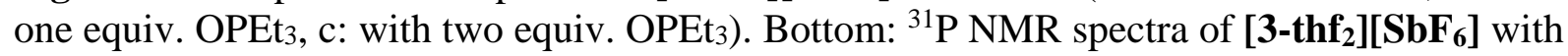
one (b) or two (c) equivalent(s) of $\mathrm{OPEt}_{3}$. 


\section{References}

1 Gaussian 16, Revision B.01, Frisch, M. J.; Trucks, G. W.; Schlegel, H. B.; Scuseria, G. E.; Robb, M. A.; Cheeseman, J. R.; Scalmani, G.; Barone, V.; Petersson, G. A.; Nakatsuji, H.; Li, X.; Caricato, M.; Marenich, A. V.; Bloino, J.; Janesko, B. G.;

Gomperts, R.; Mennucci, B.; Hratchian, H. P.; Ortiz, J. V.; Izmaylov, A. F.;

Sonnenberg, J. L.; Williams-Young, D.; Ding, F.; Lipparini, F.; Egidi, F.; Goings, J.; Peng, B.; Petrone, A.; Henderson, T.; Ranasinghe, D.; Zakrzewski, V. G.; Gao, J.; Rega, N.; Zheng, G.; Liang, W.; Hada, M.; Ehara, M.; Toyota, K.; Fukuda, R.; Hasegawa, J.; Ishida, M.; Nakajima, T.; Honda, Y.; Kitao, O.; Nakai, H.; Vreven, T.; Throssell, K.; Montgomery, J. A., Jr.; Peralta, J. E.; Ogliaro, F.; Bearpark, M. J.;

Heyd, J. J.; Brothers, E. N.; Kudin, K. N.; Staroverov, V. N.; Keith, T. A.; Kobayashi, R.; Normand, J.; Raghavachari, K.; Rendell, A. P.; Burant, J. C.; Iyengar, S. S.;

Tomasi, J.; Cossi, M.; Millam, J. M.; Klene, M.; Adamo, C.; Cammi, R.; Ochterski, J. W.; Martin, R. L.; Morokuma, K.; Farkas, O.; Foresman, J. B.; Fox, D. J. Gaussian, Inc., Wallingford CT, 2016. 